\title{
Characterization of Carbonaceous Active Materials Used for the Negative Electrode of Li-Ion Batteries and Capacitors Tsutomu TAKAMURA*
}

\author{
School of Chemical Engineering \& Technique, Harbin Institute of Technology, \\ 92 West Dazhi Street, Harbin150001, China
}

*Corresponding author: takamur@green.ocn.ne.jp

\begin{abstract}
During the course of investigating carbonaceous materials for the active materials of Li-ion batteries (LIB) or supercapacitors (SPC) we have found interesting properties and behaviors of the carbon in contact with an electrolyte containing $\mathrm{Li}^{+}$. In this article the author would like to exhibit these attractive matters. Especially use of carbon fiber (CF) attracted our attention since we can use a single fiber as the working electrode, which enables us to measure not only the conductivity change but also the volume change during Li insertion/extraction. Determination of the lithium diffusion coefficient in carbon could be performed with ease. Surprisingly propylene carbonate showed no decomposition during cathodic polarization of graphite in propylene carbonate electrolyte when we use a single graphitzed fiber. On the other hand, by the use of rounded graphite particle we suggested presence of holes on the graphene layer. We proved that homogeneous distribution of conductivity over the surface of coated electrode is the key factor to keep long cycle life.
\end{abstract}

(c) The Electrochemical Society of Japan, All rights reserved.

Keywords : Carbon Anode, Carbon Fiber, Metal Film Deposition, Li Mass Transfer

\section{Introduction}

LIB and SPC are key power devices in portable IT technology instruments and electric vehicles. Carbonaceous materials play an important role as the active material for these power sources. ${ }^{1} \mathrm{We}$ have been engaged in the $R \& D$ of carbonaceous materials for improving the negative electrode performance of LIB and SPC since 1993. During the course of the investigation on one hand, we developed several novel methods for improving the battery performance, and on the other hand, we have found by chance curious phenomena.

We have get used to use CF due to the availability of soundly specified samples, where with the use of CF we could find effective method for the performance improvement of the active material. In this article the author would like to exhibit such kinds of findings and curious phenomena for assisting to stimulate the reader's mind of scientific investigation.

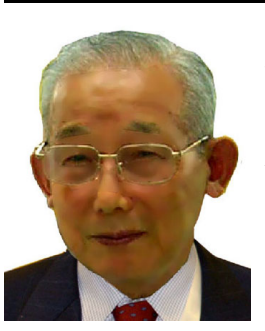

Tsutomu Takamura graduated from Tohoku University in 1954, where he obtained his doctorate in 1958. He joined with Mazda Laboratory, Tokyo Shibaura Electric Co., (Presently Toshiba Corp.) and became a postdoctoral fellow at the Case Western Reserve University with Professor Earnest B. Yeager (1968-69) in Cleveland, Ohio, USA.

Dr. Takamura was promoted to Managing Director, Chemical Laboratory, Toshiba Corp. in 1978. He became President, Toshiba Research Consulting Corp.

Dr. Takamura moved to Rikkyo University as Professor, Department of Chemistry and retired from the university due to his retiring age, then hired as Technical Advisor, Petoca Materials Ltd. (1995-2002). He was invited from Harbin Institute of Technology, Harbin, China, as Guest Professor (2002-present).

\section{Polymer Active Materials}

At the time before appearing of the widely used Lithium-ion batteries (LIB) in the market we paid our attention on the doping/ undoping of Li in the polypyrrole (Ppy) cathode electrode material for $\mathrm{Li}$ secondary batteries, and presented our paper at the International Meeting of Lithium Batteries (IMLB) held in Muenster in Germany, 1992. ${ }^{2}$ This was the first experience of the author to present a paper of Li batteries at the international meeting.

In an attempt to enlarge both the electrical conductivity and reacting surface area we tried to deposit Ppy on the surface of carbon black. The SEM image showing Ppy deposited on CB powders \#8500 (Nippon Carbon) is shown in Fig. 1, which gave quite much improved performance as, expected (Fig. 2, top line).

\section{Carbon Fibers $(\mathrm{CF})^{3}$}

\subsection{Introduction}

Production of CF is to pyrolyze a precursor of plastic resin fiber at an appropriate temperature. Various types of CF are obtainable by
His current research interests lie in the area of carbonaceous materials and silicon as the negative electrode materials of Li-ion secondary batteries, from which he extended to the study of mass transfer of $\mathrm{Li}$ in metal, underpotential deposition of $\mathrm{Li}$ on carbon surface, and ultra high capacity material of $\mathrm{Li}$ double layer capacitor. He initiated a Plant electrochemistry as a new field in electrochemistry.

Dr. Takamura was nominated as a Member of the Editorial Board, Chemical Society of Japan (1973-75), and a Member of the Board, Electrochemical Society of Japan (1974-83), and promoted to Chairman of the Editorial Board, Electrochemical Society of Japan (1987-89). He was a Chairman, Committee of Japanese Industrial Standard, (Battery Division) (1991-2002).

He received some awards from The Electrochemical Society of Japan (1974, 1996, and 2003), and Ministry of Education, Culture, Sports, Science and Technology of Japan. 


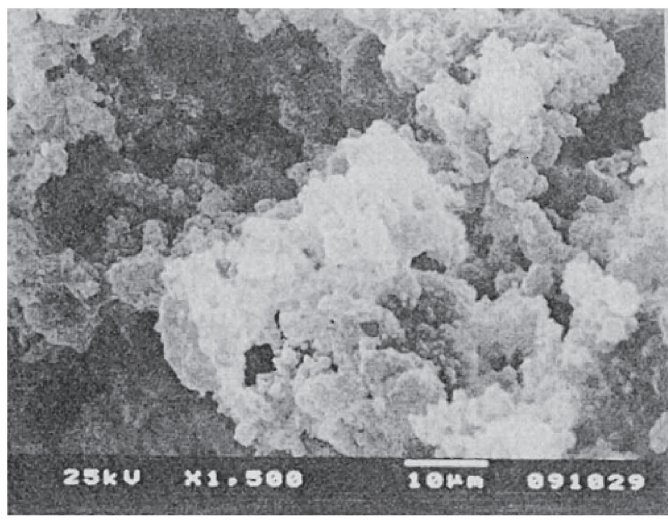

Nippon Carbon CB \#8500

Figure 1. SEM image of polypyrrole deposited actvated carbon particles (\#8500 Nippon Carbon made).

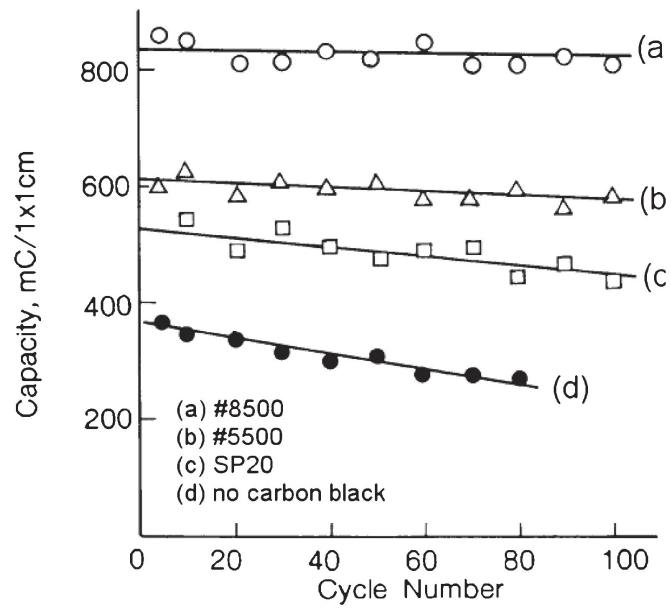

Figure 2. Cycle performance of Ppy-C and Ppy during the $1 \mathrm{C}$ rate constant current insertion/extraction in PC containing $1 \mathrm{M}$ $\mathrm{LiClO}_{4}$ at room temperature.

choosing different precursors and pyrolysis temperatures. In case of graphitized one the precursor is mesophase carbon fiber which can be converted to graphitized $\mathrm{CF}$ when heated up to $3000^{\circ} \mathrm{C}$. Figure 3 shows SEM images of $950^{\circ} \mathrm{C}$ fired $\mathrm{CF}$ obtained from mesophase $\mathrm{CF}$, where (A) and (B) are the image of low and high magnification, respectively. As inferred from the figure a single fiber can be picked up from the assembly very easily.

$\mathrm{CF}$ has surpassing properties for the purpose of the characterization of physical and electrochemical properties of the active materials as shown bellow: Usually, for the purpose of preparation of evaluating electrode, in case of powder sample the sample particles should be coated on a $\mathrm{Cu}$ sheet with a conductive additive and binder. The $\mathrm{Li}$ insertion/extraction reaction is very sensitive to the presence of coexisting material. Therefore, with the conventional coated-type electrode it is difficult to extract the surface modification effect solely. On the other hand, in case of CF sample, the fabrication of test electrode is simple enough to sandwich the sliced specimen of the integrated fiber felt between the folded metal mesh or expanded metal sheet, followed by spot-welding at several points of the peripherals of the folded metal with no binder nor conductive additives, enabling us to evaluate the modification effect free from such an influence of interfering substances. In the following sections the author would like to show the results obtained with CF samples for various kinds of evaluation.
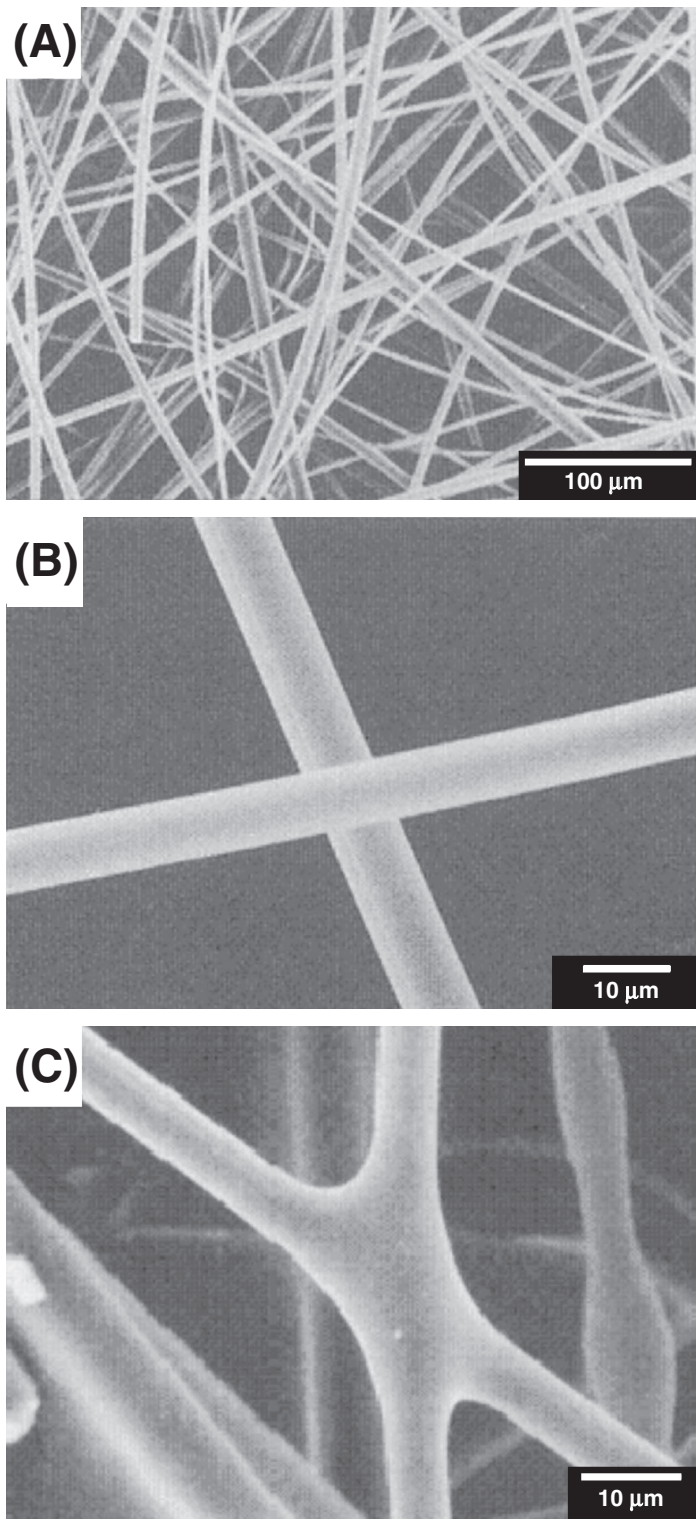

Figure 3. SEM images of carbon fiber (Melblon 950) fired at $950^{\circ} \mathrm{C}$. (A) Low magnification for integrated fiber felt, (B) High magnification image, (C) $\mathrm{C} / \mathrm{C}$ composite of Melblon 950 bound with conductive carbon prepared by heating cured resol resin.

\subsection{Characterization by measuring the electric conductivity}

The examples on CF firstly shown here are the works of in situ resistance measurements done by Mr. Ebana et al., ${ }^{4}$ and by $\mathrm{Mr}$. Ishikawa, et al. ${ }^{5}$ By the use of a single $\mathrm{CF}$ fired at different temperatures we constructed a resistance-measuring cell shown in Fig. 4. The obtained conductivity data of the $\mathrm{CF}$ samples during insertion/extraction of $\mathrm{Li}$ are shown in Fig. 5, where we see the conductivity of $1200^{\circ} \mathrm{C}$ fired sample is far less as compared with that of $3110^{\circ} \mathrm{C}$ fired sample. The electric conductivity of $\mathrm{CF}$ is strongly dependent on the prepared temperature. The most conductive one is that fired over $3000^{\circ} \mathrm{C}$, being well graphitized one, in contrast, $1200^{\circ} \mathrm{C}$ fired $\mathrm{CF}$ reveals only $10 \%$ of the conductiviey of the graphitized CF. In addition, very interesting is that the conductivity is strongly dependent on the amount of $\mathrm{Li}$ inserted in the $\mathrm{CF}$ sample. Especially, in case of $3110^{\circ} \mathrm{C}$ sample, where the internal structure is well arranged as graphite, the conductivity is proportional to the $\mathrm{Li}$ amount, and the proportionality changed at about $100 \mathrm{Cg}^{-1}\left(360 \mathrm{mAhg}^{-1}\right)$, which is close to the amount 


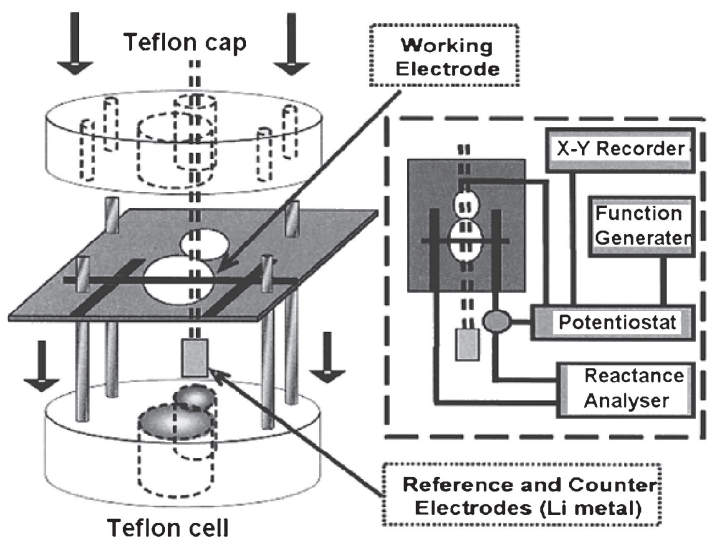

Figure 4. In situ situ cell for the measurement of resistance of single CF.

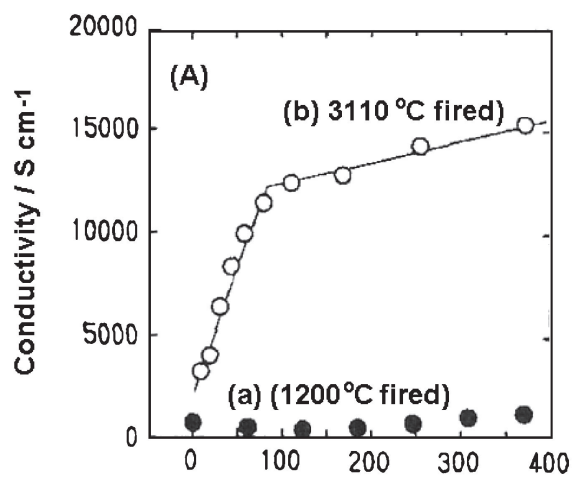

Amount of $\mathrm{Li}$ charge inserted / $\mathrm{C} \mathrm{g}^{-1}$

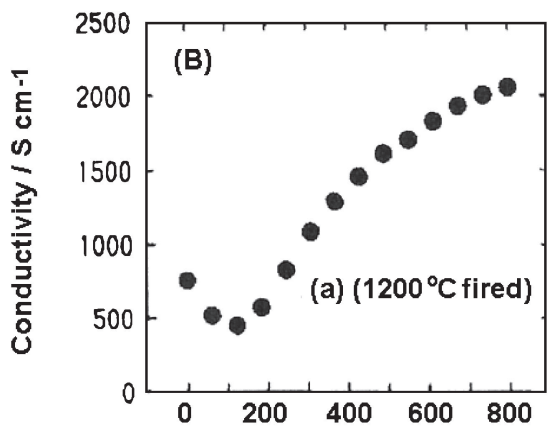

Amount of Li charge inserted $/ \mathrm{C} \mathrm{g}^{-1}$

Figure 5. Electric conductivity of $\mathrm{CF}$ as a function of inserted amount of $\mathrm{Li}$ in the carbon. (A) For two kinds of CF fired at $3110^{\circ} \mathrm{C}$ and $1200^{\circ} \mathrm{C}$. (B) For $1200^{\circ} \mathrm{C} \mathrm{CF}$.

corresponding to stage $1\left(372 \mathrm{mAhg}^{-1}\right)$. This implies that the conductivity is closely related to the stage arrangement.

The second example is those obtained by Miss Uratani, et al., ${ }^{6}$ in regard to the microscope observation on the expansion and shrinking of the $\mathrm{CF}$ diameter during $\mathrm{Li}$ insertion/extraction. The $\mathrm{CF}$ sample was Carbonic 3110 (Petoca Materials, fired at $3110^{\circ} \mathrm{C}$, the fiber diameter being $27 \mu \mathrm{m})$ and positioned in the Teflon cell similar to Fig. 4, where a microscope was set at the top of the cell and the image was monitored with a digital video camera. The fiber was set in a 1:1 (v/v) mixture of ethylene carbonate (EC) and dimethyl carbonate (DMC) containing $1 \mathrm{M} \mathrm{LiClO}_{4}$ and polarized stepwise at every $200 \mathrm{mV}$ from $2.0 \mathrm{~V}$ vs. $\mathrm{Li} \mid \mathrm{Li}^{+}$to $0 \mathrm{~V}$, then polarized backward from 0 to $2.0 \mathrm{~V}$. Figure 6 shows current/potential curve (A) and corresponding diameter/potential curve (B). As seen in the figure the diameter increases during

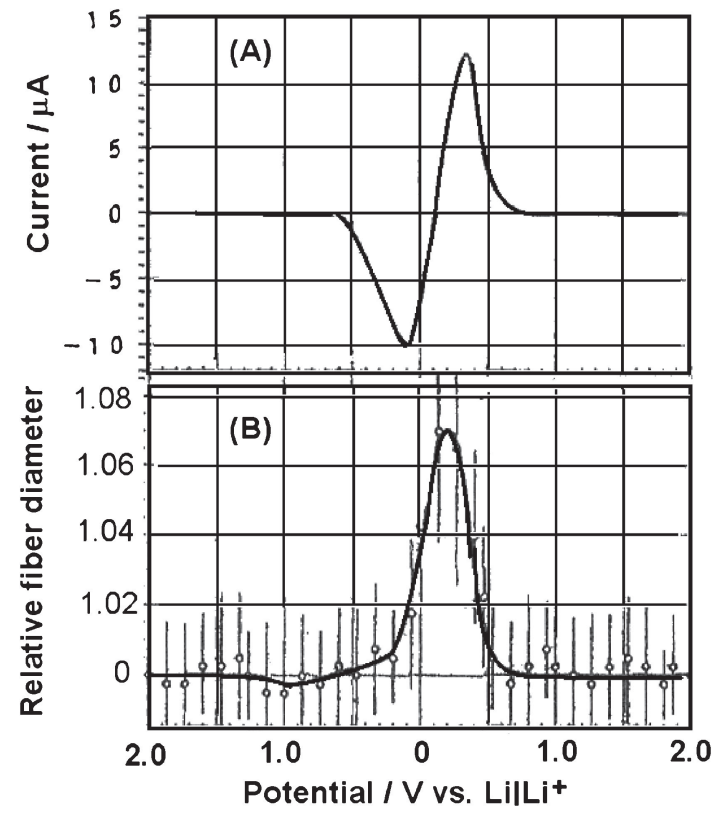

Figure 6. Current-potential curve of graphitized $\mathrm{CF}$ during $\mathrm{Li}$ insertion and extraction (A), and the potential dependency of the fiber thickness measured with a microscope during the Li insertion and extraction (B).

Li insertion and decreases during $\mathrm{Li}$ deinsertion. The maximum increase in diameter was about $7 \%$. Thus we could verify the increase in diameter of $\mathrm{CF}$ due to the insertion of $\mathrm{Li}$, the behavior being reversible.

Not only the diameter swelling and shrinking but also the color change during $\mathrm{Li}$ insertion/extraction was observed. During the course of Li insertion, the color of the fiber surface was changed from black to blue, copper color, then golden color at the maximum amount of insertion. This color change was quite much reversible as well.

\subsection{Determination of diffusion rate of $\mathrm{Li}$ in carbon}

Ascertaining the reliable value of diffusion rate of $\mathrm{Li}$ in carbon is important not only for advancing the basic science on carbon materials but also for improving the design of the negative electrode of LIB. Electrochemical method is convenient for the determination of the diffusion coefficient of Li but it is necessary to prepare the test electrode for this purpose. In general the electrode of the carbon sample is prepared to coat the sample powder on a $\mathrm{Cu}$ foil together with a binder and electro-conductive additive (viz., VGCF, of acetylene black powder), being served for the measurement of potential step chronoammperometry. In this case we have to consider on the situation of the electrode, which is an agglomeration of a number of active material particles together with a particles of conductive additive bound by the binder. That situation is complicated and very far from the situation of one carbon particle to which $\mathrm{Li}$ is getting into and out. Therefore, the data obtained with such a coated electrode involve the interference of such complicated situations, implying that the obtained data will not be trustable one.

Uchida and Matsue group developed a microscopic method for evaluating electrochemical properties of a single particle. ${ }^{7}$ Using this method they could obtain the trustable results free from the influence associated with the above-mentioned interference problems. Instead, use of CF is so simple for realizing a similar condition that enables us to obtain trustable results on carbonaceous materials with ease. By the use of a single fiber of graphitized carbon fiber (Melblon 3100: Product of Petoca Materials, Co., Ltd. Tokyo, Japan, mesophase CF graphitized at $3100^{\circ} \mathrm{C}$ ) Mr. Yamaguchi 


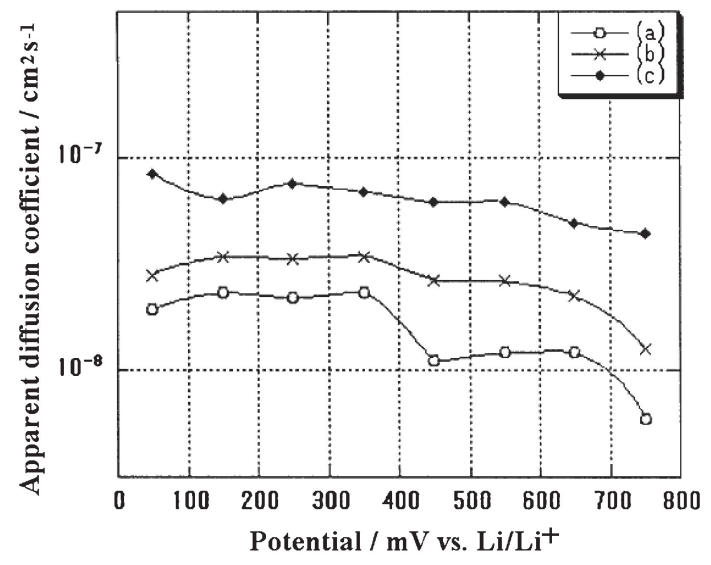

Figure 7. Potential dependency of Li diffusion coefficient of $\mathrm{CF}$ fired at $800^{\circ} \mathrm{C}$. (a) Pristine. (b) heated at $250^{\circ} \mathrm{C}$ in vacuum, (c) Treated by MOT after Ag film deposition.

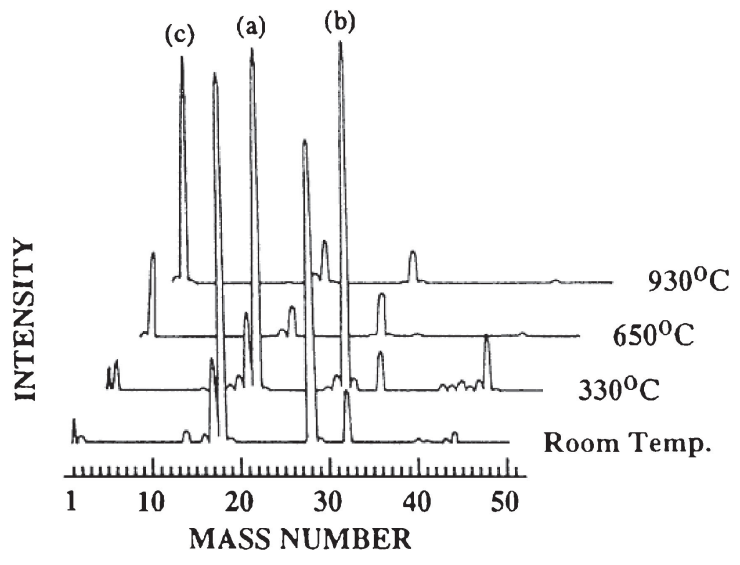

Figure 9. Gas mass spectra of $1000^{\circ} \mathrm{C} \mathrm{CF}$ in vacuum.
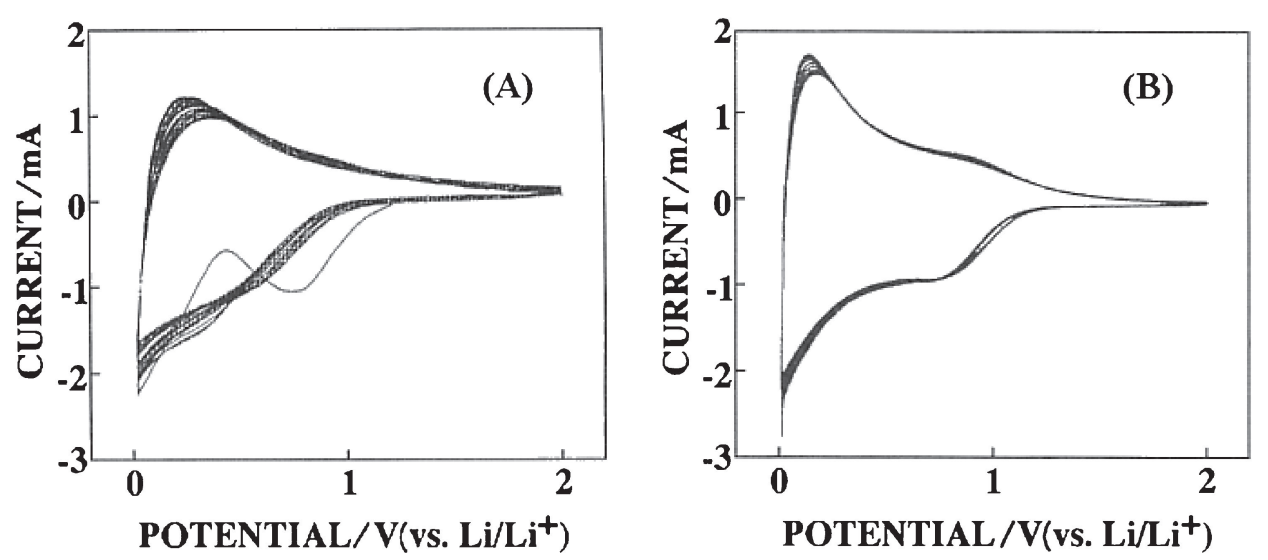

Figure 8. Cyclic voltammograms of $1000^{\circ} \mathrm{C}$ fired $\mathrm{CF}$ measured in $\mathrm{PC}$ containing $1 \mathrm{M} \mathrm{LiClO}_{4}$ with potential scan rate of $1 \mathrm{mV} \mathrm{s}$. (A) Pristine sample. (B) After MOT at $500^{\circ} \mathrm{C}$ for $30 \mathrm{~min}$.

applied chronopotentiometric method and could obtain the diffusion coefficient of $\mathrm{Li}$ in graphite, the value being as high as $1.5 \times 10^{-6} \mathrm{~cm}^{2} \mathrm{~s}^{-1}$ after the mild oxidation treatment (MOT) during extraction process at $50 \mathrm{mV}$ vs. $\mathrm{Li}_{\mid} \mathrm{Li}^{+}{ }^{8}$ This value is the highest among the literature values ever reported, implying the value is the most trustable.

Similarly, Omae and coworkers evaluated Li apparent diffusion coefficient $\left(D_{\text {Liapp }}\right)$ in the lower temperature fired carbons. ${ }^{9}$ The $D_{\text {Liapp }}$ values were found to increase by increasing the temperature of the heat-treatment (Fig. 7). Further, the treatment involving Ag film deposition followed by mild oxidation caused increasing of the value of $D_{\text {Liapp }}$ as shown in Fig. 7, curve (c).

\subsection{Surface modification by heat-treatment}

At the time of beginning of the research on the anode material we examined $\mathrm{CF}$ fired at low temperature, say $1000^{\circ} \mathrm{C}$. The cyclic voltammogram $(\mathrm{CV})$ in the conventional electrolyte was not steady as shown in Fig. 8(A). We considered this is due to the presence of unstable entities in the matrix, and so we tried to remove these unfavorable entities by heating with a large amount of $A B$ since $A B$ has a reducing tendency. After heating at $500^{\circ} \mathrm{C}$ for $30 \mathrm{~min}$. the resulting CV was satisfactory as shown in Fig. 8(B). We presented these results at the Symposium of Materials Research Society in 1995..$^{10,11}$

Prof. E. Peled of Tel Aviv University joined in this symposium. He appeared to be quite much impressed since it had been very difficult for him to solve the issue of removing the irreversible tendency until that time. He published his paper just later on stating that "mild oxidation" is very important for the surface cleaning of the carbonaceous materials. ${ }^{12}$ The "mild oxidation treatment (MOT)" at an appropriate temperature in the presence of favorable amount of oxygen, is an important method to clean up the surface of the carbonaceous samples by burning off the surface contaminant. In addition to his pointing out, not only the surface but also the internal contaminant causing to the initial capacity loss can be removed, which is shown below.

In general, carbonaceous sample is not necessarily in fully aged condition. As seen in Fig. 9 even the $1000^{\circ} \mathrm{C}$ fired sample gave off some gases from matrix when heated at lower temperature. Such kind of non-aged carbon sample can be cleaned by keeping it at high temperature. ${ }^{13,14}$

\subsection{Surface modification by covering with metal films on CF}

Attempting to enhance the rates of $\mathrm{Li}$ insertion/extraction on the carbon surface we tried to cover the surface with a metallic film by vacuum deposition. At first we selected Pd metal as the depositing film. ${ }^{15}$ We expected that the reaction rate should be quite much enhanced because Li is very similar to hydrogen whose affinity for Pd is very large. We preferred to adopt a vacuum deposition method to wet method for covering with a metal film since this method is free from contamination of foreign entities. We measured CVs for fiber samples with and without vacuum-deposited metal film, and compared both. Unfortunately the results were against the expectation. Being contrary to our expectation, the anodic peak due to the 


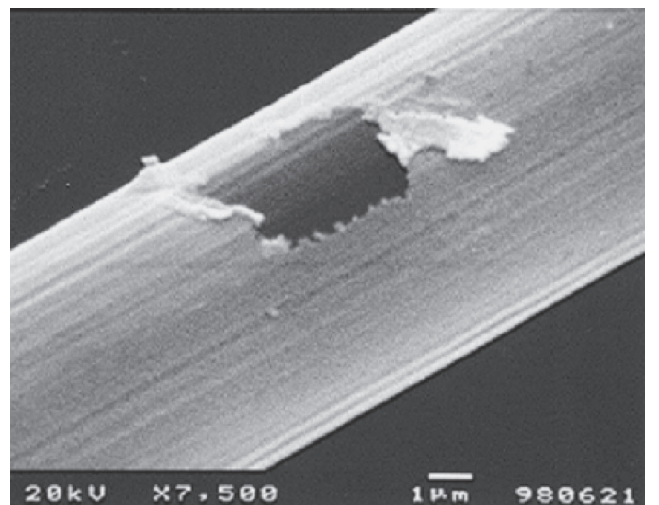

Figure 10. $300 \AA$ thick $\mathrm{Ag}$ film deposited $\mathrm{CF}$ prepared at $3100^{\circ} \mathrm{C}$.

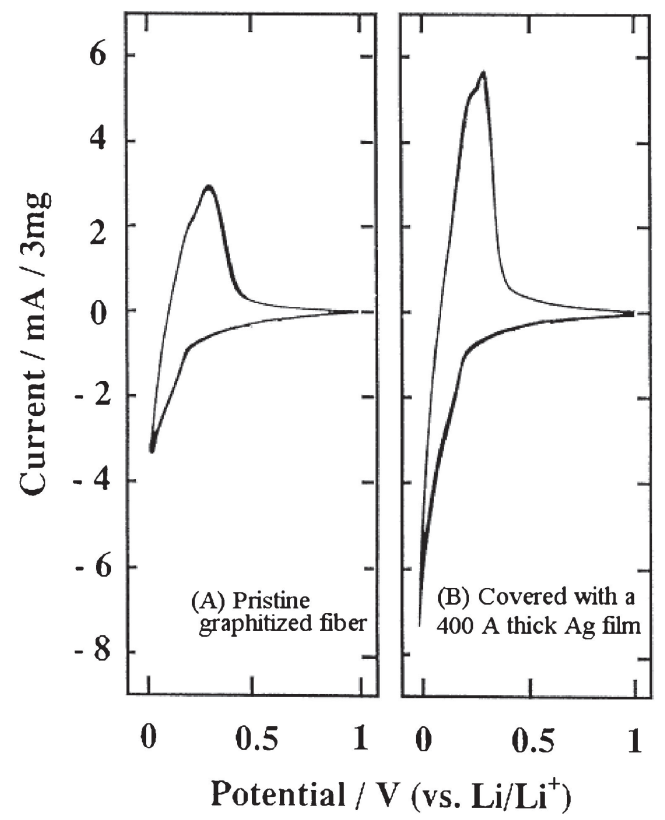

Figure 11. Cyclic voltammograms of graphtized CF (Melblon 3100 ) in $\mathrm{EC} / \mathrm{DMC}$ containing $1 \mathrm{M} \mathrm{LiClO}_{4}$ with a scan rate of $1 \mathrm{mV} \mathrm{s}^{-1}$. (A) Pristine, (B) Covered with a vacuum deposited $400 \AA$ thick Ag film.

extraction of Li from the graphitized fiber was diminished for Pd covered sample. At that time we had no information on the SEI (Solid Electrolyte Interphase). Later on we ascribed this phenomenon to the inhibiting effect of SEI formed on the Pd film.

Then, we examined the effect of $\mathrm{Ag}$ covering over the graphitized carbon fiber. Figure 10 shows the SEM image of graphitized carbon fiber covered with a $300 \AA$ thick Ag film, where a part of the film was intentionally scratched off for identifying the presence of the film. Contrary to the case of Pd film, the $\mathrm{Li}$ insertion/extraction reaction was quite much enhanced by the $\mathrm{Ag}$ film deposition as shown in Fig. 11, where CV peak height is shown to be enhanced two times after the deposition of a $400 \AA$ thick $\mathrm{Ag}$ film. ${ }^{16}$

We evaluated the effect of the metal film deposition based on impedance measurement. F. Kikuchi, et al. published a paper on the impedance measurement. ${ }^{17}$ It is very interesting that when the thickness of Ag film is as thin as $200 \AA$ not only the film impedance but also the charge transfer resistance are larger than those of pristine sample, while those were decreased for the case of thicker film. This may be due to the structure inhomogeneity for the thinnest film. Anyhow, covering with a Ag film having appropriate thickness assists to enhance the $\mathrm{Li}$ insertion/extraction reaction rate.

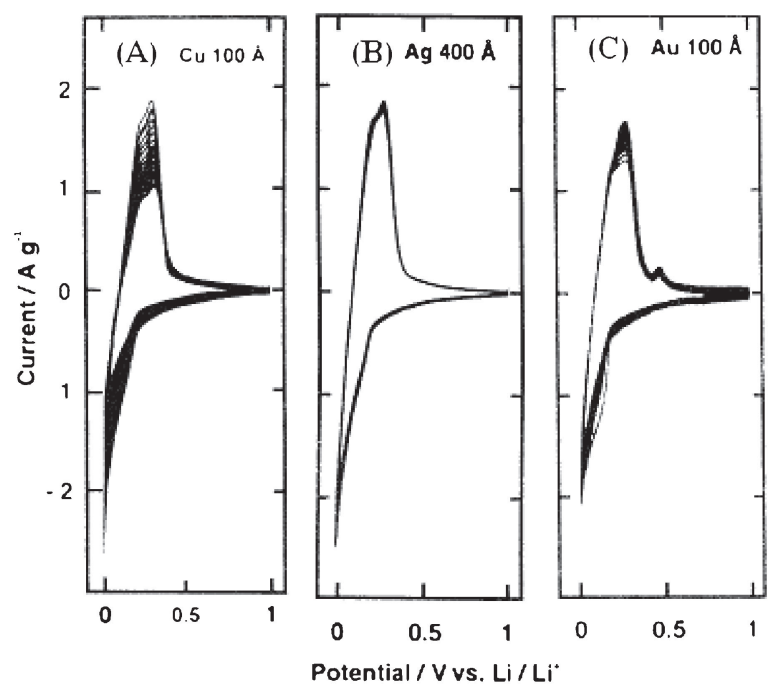

Figure 12. Cyclic voltammograms of surface modified graphtized CF (Melblon 3100) in EC/DMC containing $1 \mathrm{M} \mathrm{LiClO}_{4}$ with a scan rate of $1 \mathrm{mV} \mathrm{s}^{-1}$. (A) With a $100 \AA$ thick Cu film, (B) With a $400 \AA$ thick Ag film, (C) With a $100 \AA$ thick Au film.

We challenged to clarify the reason why deposition of $\mathrm{Ag}$ film on the surface of carbon caused to enhance the $\mathrm{Li}$ extraction peak height. We examined several metals including Ag on the enhancement effect, i.e., $\mathrm{Cu}, \mathrm{Au}, \mathrm{Ag}, \mathrm{An}, \mathrm{Zn}$, and $\mathrm{In}^{18}$ All the metals showed peak enhancement effect with optimum thickness around $150-400 \AA$ in spite of causing poorer cycle performance. The poorer cycle performance can be elucidated by the results of the following investigation.

Examination of cycleability for $\mathrm{Cu}$ and $\mathrm{Au}$ film covered $\mathrm{CF}$ was performed, where the metals belong to the same group IA in the Periodic Table of Elements. The CVs of graphitized carbon fiber covered with these three metals are shown in Fig. 12. It is interesting to note that the cycleability of these samples differs depending of metal species. The most stable one is that of $\mathrm{Ag}$ covered sample. These metals make alloys with $\mathrm{Li}$ except $\mathrm{Cu}$. Alloy formation and disappearing during cycling will cause to break the homogeneous films due to the repetition of swelling and shrinking. This cannot to be ascribed to the cause of irreversibility since $\mathrm{Cu}$ forms no Lialloys. We examined two-layered sample, i.e., $\mathrm{Cu}$ covered sample was over-layered with Ag covering, and vise versa. One example is shown in Fig. 13, where covering of a single layered $\mathrm{Cu}$ (a) and two ply film of Ag covering over the $\mathrm{Cu}$ film covering fiber (b). We see that the cycleability was quite much improved by covering a $\mathrm{Ag}$ layer over the $\mathrm{Cu}$ film.

These results can be elucidated when we presume that the SEI formed on a $\mathrm{Cu}$ film is not stable to keep the same surface situation, while Ag film gives stable performance. The $\mathrm{Cu}$ film covered with $\mathrm{Ag}$ film is staying away from direct contact of $\mathrm{Cu}$ and electrolyte. Therefore, the surface condition plays an important role for realizing good cycleability.

Graphitzed fiber revealed higher peak height of Li insertion/ extraction when treated MOT as shown above. ${ }^{12-14}$ Inquiring into the process of metal film depositin in vacuum, at first the metal vapor atom should hit on the carbon surface to become into deposited solid with a loss of enegy of translational motion, releasing considerable amount of heat. Therefore, the resulting surface condition of the carbon fiber is very similar to that after MOT. Accordingly, the enhancement of the CV peak height after the metal film deposition is not necessarily ascribed to the formation of metal surface. 


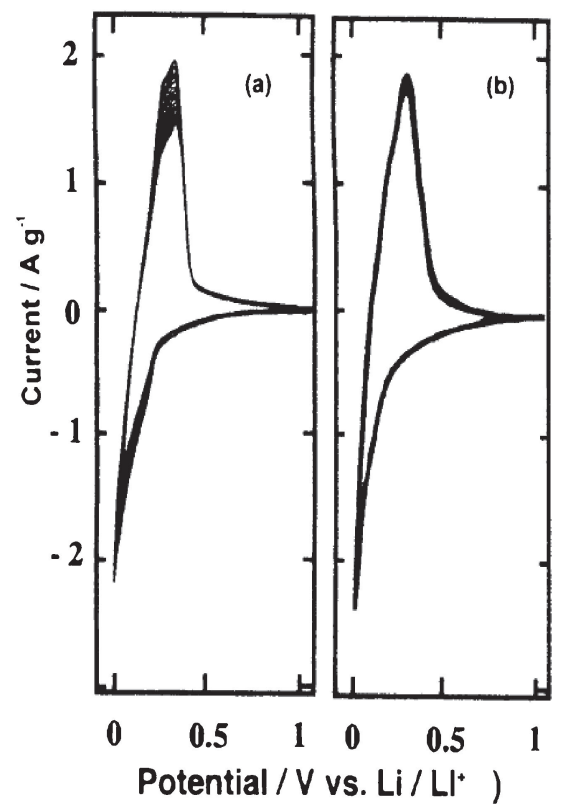

Figure 13. CVs of surface modified graphtized CF (Melblon 3100 ) in EC/DMC containing $1 \mathrm{M} \mathrm{LiClO}_{4}$ with a scan rate of $1 \mathrm{mV} \mathrm{s}^{-1}$. (a) Covered with a $200 \AA$ thick $\mathrm{Cu}$ film, (b) Case of (a) was over-layered with a $200 \AA$ thick Ag film.

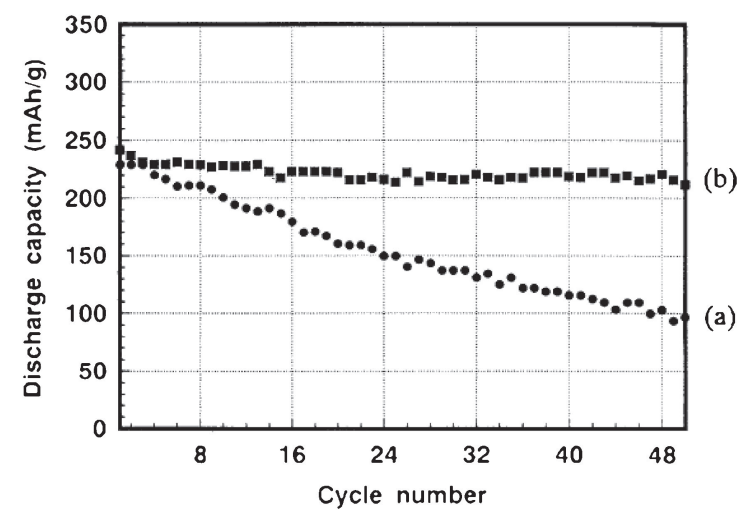

Figure 14. Cycle performance of $950^{\circ} \mathrm{C}$ fired $\mathrm{CF}$ in $\mathrm{PC}$ containing $1 \mathrm{M} \mathrm{LiClO}_{4}$ under $1.5 \mathrm{C}$ rate. (a) Simple integrated fiber felt, (b) $\mathrm{C} / \mathrm{C}$ composite bound with conductive carbon binder of resol.

\subsection{Use of thermosetting resin to form conductive binder for attaining long cycleability}

The cycleability of $\mathrm{Li}$ insertion/extraction reaction was not satisfactory in spite of application of elaborate MOT treatment. The reason is supposed to be due to the imperfect mutual contact among the fibers in the felt as inferred from Fig. 3(A), (B), which show the electric contact among the fibers to be point to point, which is too simple to keep tight contact. We challenged to improve the cycleability by taking favorable electrical contact among the fibers. The strategy is to apply a kind of resin glue (resol resin, a kind of phenol resin) to bind the fibers together, followed by heating the resin to turn to the electric conductive carbonaceous material. ${ }^{19}$

Figure 3(C) shows the resulting $\mathrm{C} / \mathrm{C}$ composite obtained with that resin. The cycle performance results were compared with this conductive binder $\mathrm{C} / \mathrm{C}$ composite and that of simple compressed fiber felt, which is shown in Fig. 14. The cycle performance of the $\mathrm{C} / \mathrm{C}$ composite is favorable (Fig. 14(b)) in contrast to that of simply compressed felt sample (Fig. 14(a)). In such a way we could acquire the key factor for obtaining a long cycle life of the active material of LIB.

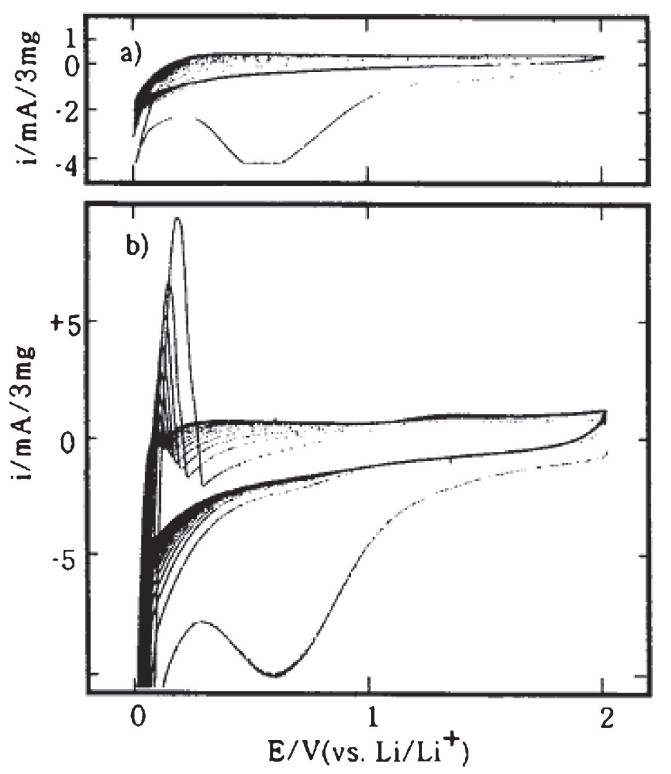

Figure 15. Cyclic voltammograms of activated carbon fiber (Toho Tenax FW510) in $\mathrm{PC}$ containing $1 \mathrm{M} \mathrm{LiClO}_{4}$ with potential scan rate of $1 \mathrm{mV} \mathrm{s}^{-1}$. a) Pristine sample, b) After MOT of pristine sample.

\subsection{Underpotential deposition (UPD) of Li on carbon surface}

Adsorption of ions on the surface of carbon electrode in contact with an organic electrolyte provides an interesting phenomenon. Fortuitously we encountered the phenomenon of "underpotential deposition of $\mathrm{Li}$ on the carbon electrode surface". One day, Mr. Awano, graduate student (Rikkyo Univeersity), tried to obtain CVs with activated carbon fiber before and after the MOT. The CVs he obtained rervealed a distinct sharp peak near the potential of metallic $\mathrm{Li}$ deposition, viz., a little positive side of $0 \mathrm{~V}$ vs. $\mathrm{Li} \mid \mathrm{Li}^{+}$as shown in Fig. 15(b). At one glance the author felt that is due to the anodic dissolution of deposited metallic $\mathrm{Li}$, and rebuked him that never go to far cathodic side where deposition of metallic lithium would take place. Had we inspect more precisely to compare the CVs before and after the MOT the author might not rebuke since Fig. 15(a) shows no such anodic peak in spite of measuring with the same sample.

At first, the author could not perceive that such kind of anodic peak is due to the anodic oxidation of the underpotentially deposited $\mathrm{Li}$ on carbon. We misunderstood the peak to be due to the anodic dissolution of deposited metallic lithium. Afterwards, we had to revise this argument to that the cause of the big peak near the potential of $\mathrm{Li} \mid \mathrm{Li}^{+}$to be caused by the surface oxidation of underpotentially deposited surface $\mathrm{Li}^{20}$ This kind of idea was induced by the paper of Aurbach and coworkers ${ }^{21}$ on the underpotential deposition of $\mathrm{Li}$ on a gold electrode. "Faradaic adsorption (FAd) of Li" at the metal electrode other than carbon may be expected to take place, but to that date no attention appeared to have been paid on carbon surfaces. In our preliminary experiments the test electrode was fabricated by sandwiching the sample of carbon fiber felt between two $\mathrm{Ni}$ grid sheets. Neither binder nor additives were used in order to avoid unfavorable surface contamination, where the possibility of the taking place of FAd is high since the reaction is very sensitive to the surface condition. Contaminated surface is supposed not to allow FAd. This new knowledge induced us to examine with a graphitized carbon fiber whose surface is more idealized as compared to that of activated carbon fiber felt. Immediately we examined the graphitized carbon fiber electrode with and without MOT. 

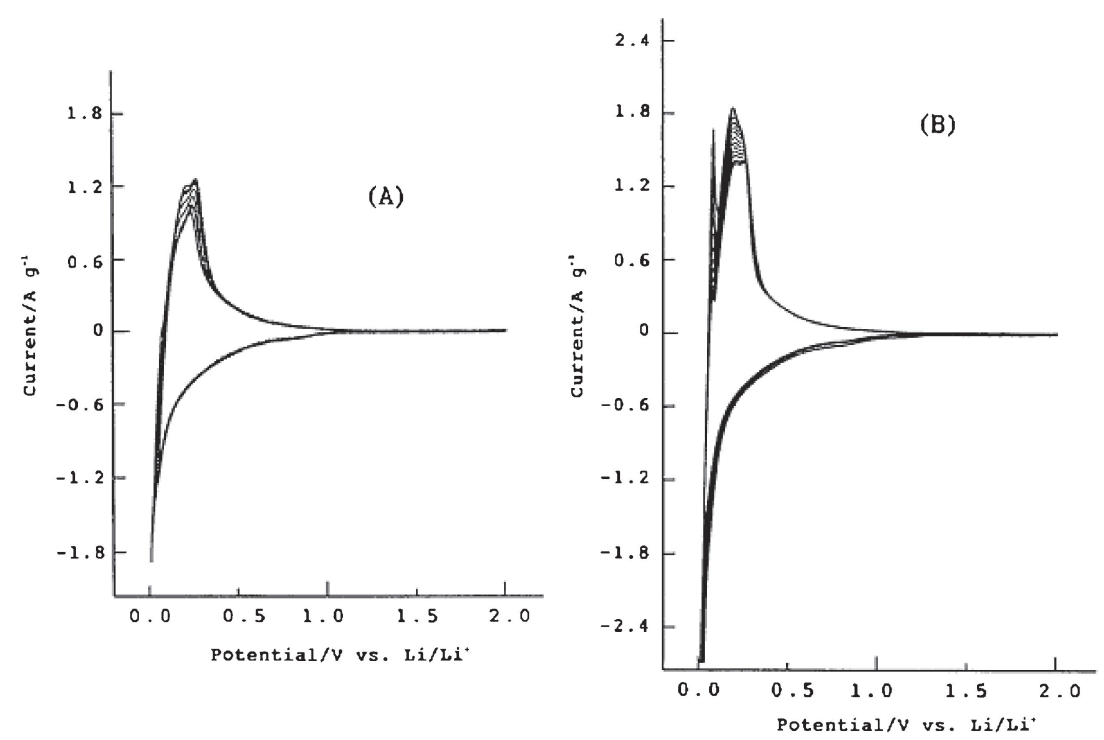

Figure 16. Cyclic voltammograms of graphitized CF (Melblon 3100) in EC/DMC (1:1, v/v) containing $1 \mathrm{M} \mathrm{LiClO}_{4}$ with a potential scan rate of $1 \mathrm{mV} \mathrm{s}^{-1}$. (A) Pristine sample, (B) After MOT on (A).
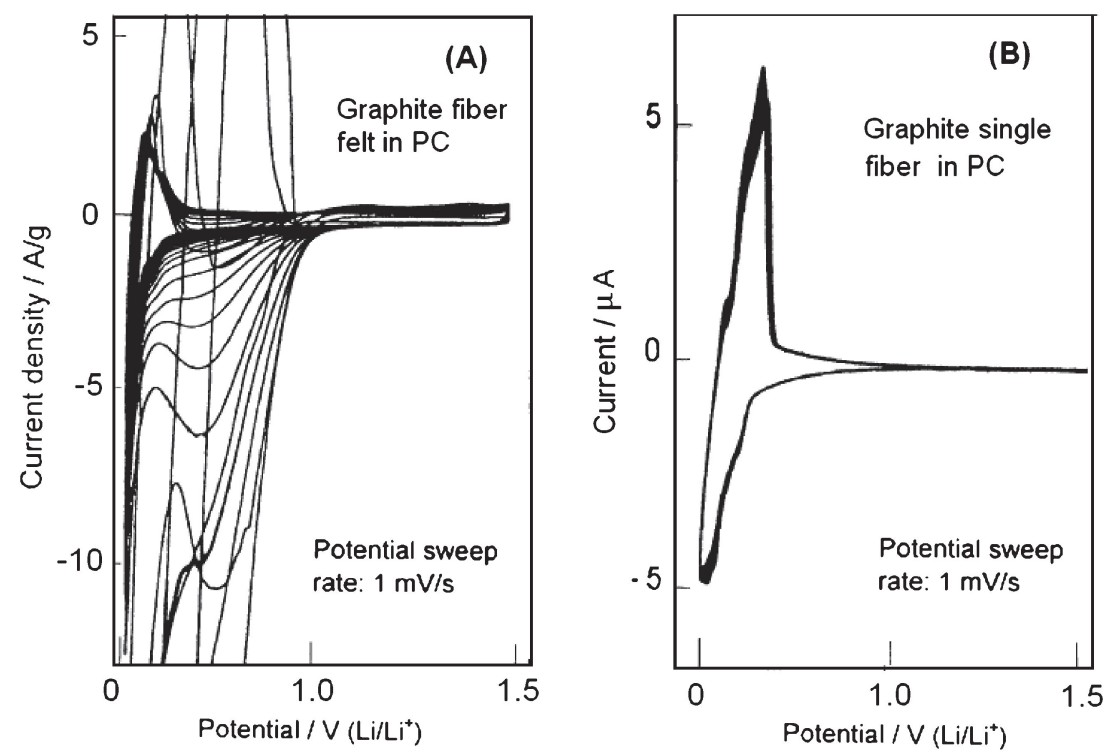

Figure 17. Cyclic voltammograms of graphitized CF (Melblon 3100) in $\mathrm{PC}$ containing $1 \mathrm{M} \mathrm{LiClO}_{4}$ with a potential scan rate of $1 \mathrm{mV} \mathrm{s}$. (A) Integrated fiber felt, (B) A single fiber.

Figure 16 shows the results, ${ }^{20}$ where two $\mathrm{CVs}$ of ideally graphitized carbon fiber (Melblon 3100) obtained before (A) and after the MOT (B). The high cathodic peak is due to the insertion of $\mathrm{Li}$ in the fiber matrix and the anodic one is, to that of extraction of Li. We can recognize an acute anodic peak appearing at around $80 \mathrm{mV}$ on (B) but no peak there on (A). This acute peak is just the peak due to the anodic dissolution of FAd. Later on we could recognize that the peak due to FAd of $\mathrm{Li}$ can be seen on the CVs after MOT irrespective of the kind of carbon material.

\subsection{Stability of propylene carbonate on the graphite anode}

It is well known that propylene carbonate (PC) is decomposed when it is in contact with the surface of graphite under cathodic polarization. An example of the decomposition is shown in Fig. 17(A), where we see violent irregular current lines, especially on the cathodic branch in (A). The current line decreases during cycle until fading. The color of the electrolyte solution became black due to the suspension of carbon powders formed by the crashing of the fiber felt during the decomposition. Although PC is a good solvent but cannot be used for the active material of graphite. In contrast, mesophase carbon fired at lower temperature is stable to give stationary curves.

The destruction of graphite electrode in PC is so well-known that use of PC had been avoided for the commercial LIB. By chance, however, we found no such a violent situation when we use a single fiber electrode measurement as shown on Fig. 17(B). ${ }^{21}$ We tried to find out the reason why a single fiber electrode is stable in PC even though the integrated fiber mat of the same material causes to decompose PC. Mr. K. Yamaguchi, who was a player of Japanese archery (Rikkyo University), decided to perform a delicate and skilful work with $20 \mu \mathrm{m}$ diameter graphitized carbon fiber. He prepared two electrode systems, i.e., the one is composed of ordered carbon fibers pasted in order on the tip of a $\mathrm{Ni}$ wire with electric conductive glue (Fig. 18 top (A)), and the other, composed of tousled fibers (Fig. 18 top (B)). ${ }^{23}$ The resulting CVs with these fiber assemblies are shown in Fig. 18 bottom CVs, where we see 
(A)

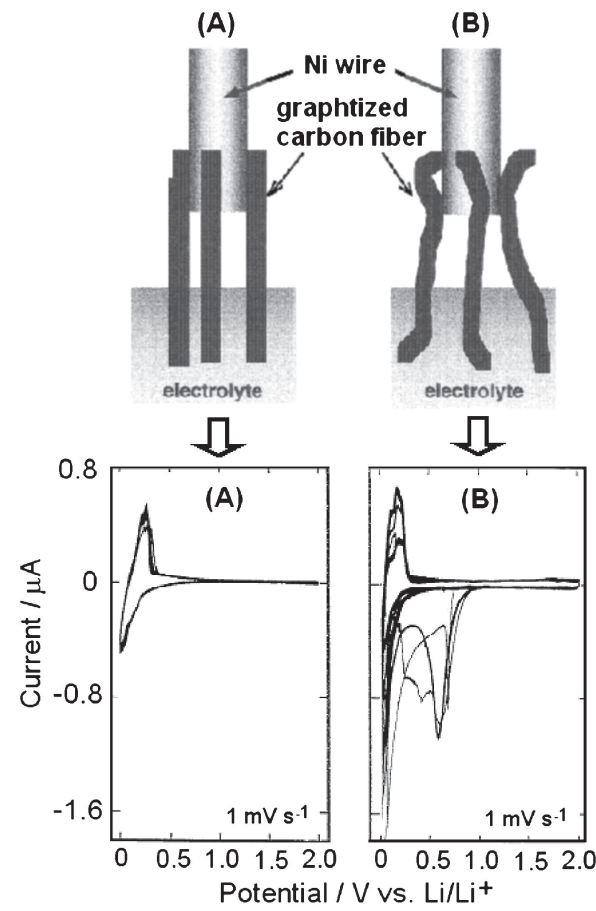

Figure 18. Electrode arrays of Melblon 3100 (top) and corresponding CVs obtained with these samples in PC containing $1 \mathrm{M}$ $\mathrm{LiClO}_{4}$.

suppressed decomposition current for (A) and heavy decomposition current for (B). From these features we concluded that decomposition of PC on a graphite electrode is induced by the inhomogeneous distribution of potential around the electrode. The electrochemical reaction on the graphite electrode in PC is supposed not simple but complicated depending on the polarization potential, implying that co-operation of different reactions causes to solvent co-intercalation into the graphite edge plane to decompose the graphite structure. ${ }^{24}$ Such kind of deduction is possible to be drawn solely with the single fiber experiment.

\subsection{Prove of Li mass transfer through metal films}

At the time of surface modification experiment with metal film deposited on the surface of carbon fiber, we carefully inquired into the mass transfer process of $\mathrm{Li}$ from electrolyte to carbon fiber by watching the SEM image shown in Fig. 10. During cathodic polarization, $\mathrm{Li}^{+}$in the electrolyte should be reduced at the metal surface and get into the fiber electrode, and vise versa. This means that $\mathrm{Li}$ at first getting into the metal film and move through the film onto the carbon surface. Therefore, "Li can move through the metal film". This phenomenon appears very natural but we were reminded the common sense that metal atom is difficult to move freely in a solid metal at room temperature. At the Battery Symposium in Japan in 2002, the author pointed out this phenomenon to the audience during my talk. But all the audience appeared not agreeing with my opinion that Li moves freely in a metal film. This induced the author to decide to verify this phenomenon by experiment. ${ }^{25}$

Professor Sekine of Rikkyo University kindly machined to obtain a bipolar cell from a Teflon rod, where two cell compartments are facing together and a $3 \mu \mathrm{m}$ thick $\mathrm{Cu}$ foil was sandwiched between the two compartments (Fig. 19). In Cell 1 EC/DMC 1:1 v/v containing $1 \mathrm{M} \mathrm{LiClO}_{4}$ was filled and in Cell 2 that containing $\mathrm{NaClO}_{4}$ was filled, aliquot of solution in Cell 2 being pipetted out at open-circuit potential and analyzed on $\mathrm{Li}$ by atomic absorption analysis. Then, the $\mathrm{Cu}$ electrode in Cell 2 was polarized at sufficiently anodic potential and that in Cell 1 was set at $10 \mathrm{mV}$ vs. $\mathrm{Li} \mid \mathrm{Li}^{+}$, followed by pipetting out the solution in Cell 2 from time
Bipolar working electrode

( $3 \mu \mathrm{m}$ thick copper foil)

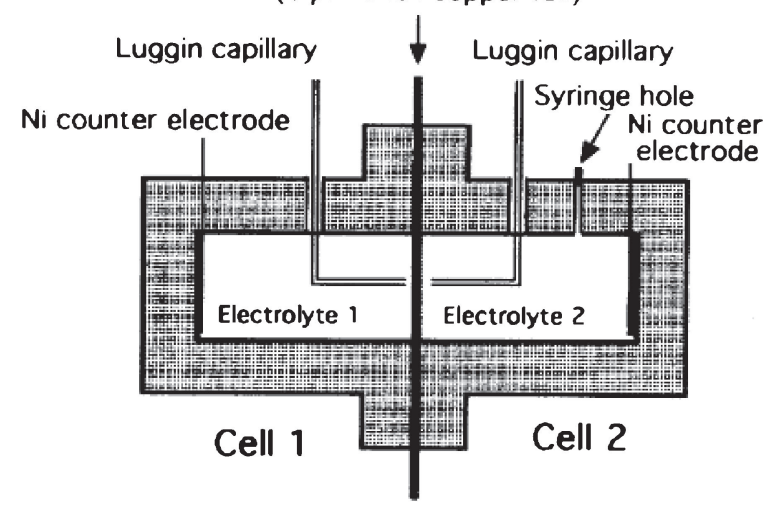

Figure 19. Bipolar cell system used for verifying Li mass transfer in a 3-micrometer thick $\mathrm{Cu}$ foil.

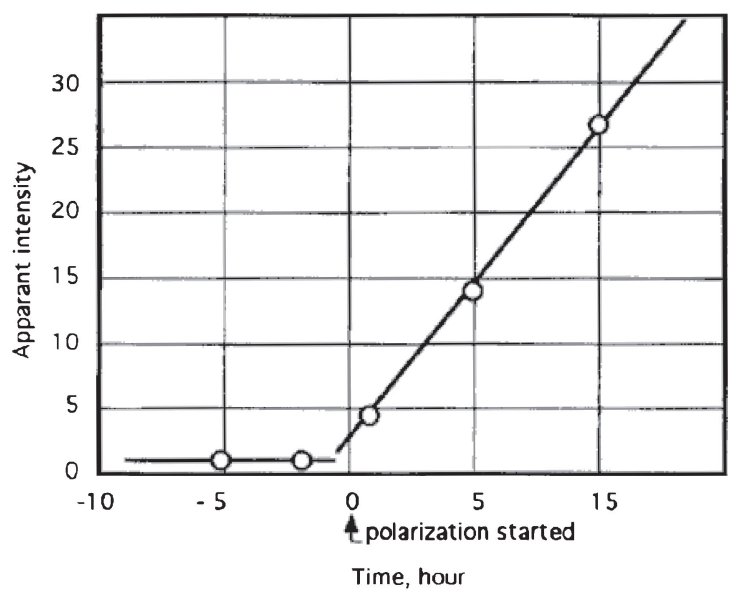

Figure 20. Concentration-time curve of $\mathrm{Li}^{+}$in Cell 2 during cathodic polarization of $\mathrm{Cu}$ electrode in Cell 1 before and after the potential setting.

to time. The solution was analyzed for $\mathrm{Li}$ by atomic absorption spectrometry. The amount of Li in Cell 2 was zero at the time of open-circuit potential indicating no leakage from Cell 1 to Cell 2, but started to increase after setting of potential in Cell 1 at $0 \mathrm{mV}$ as shown in Fig. 20. ${ }^{25}$ In this manner as stated above, we could verify that $\mathrm{Li}$ moves through $\mathrm{Cu}$ at the time of cathodic polarization of $\mathrm{Cu}$ in Cell $1 .^{26}$

\section{Presence of Holes on the Graphene Plane}

The energy of accommodation of lithium in graphite differs depending on the state of accommodation. In case of full accommodation state, it is called to be "Stage 1" having the highest energy. The next higher amount accommodation state corresponds to the called "Stage 2", and so on. The feature of each stage is illustrated in Fig. 21, where black circle shows lithium particle. The potential of intercalation or deintercalation differs depending on the stage, and the stage 1 takes place at the most cathodic potential, followed by stage 2 , etc. The actual potential profile can be observed on the differential chronopotential diagram. ${ }^{27}$

Once the author encountered a problem when watching Fig. 21. That is on the insertion/deinsertion behavior. At the time of increasing insertion amount of Li from stage 3 to stage 2, how can $\mathrm{Li}$ atom be situated without deinsertion from that array. This problem is just similar to the insertion of $\mathrm{Li}$ in the commercial 

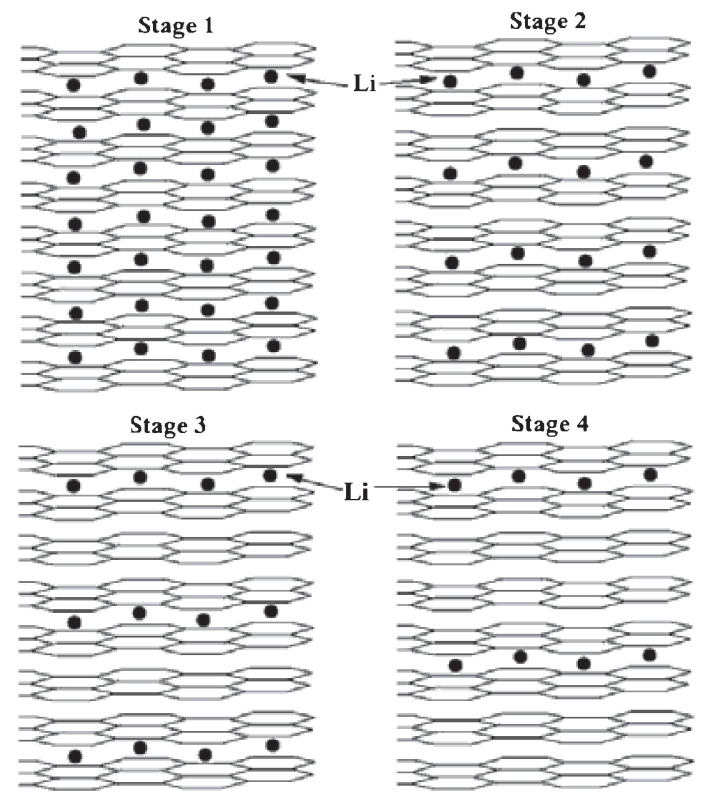

Figure 21. Illustration of $\mathrm{Li}$ intercalation stages in graphite structure.
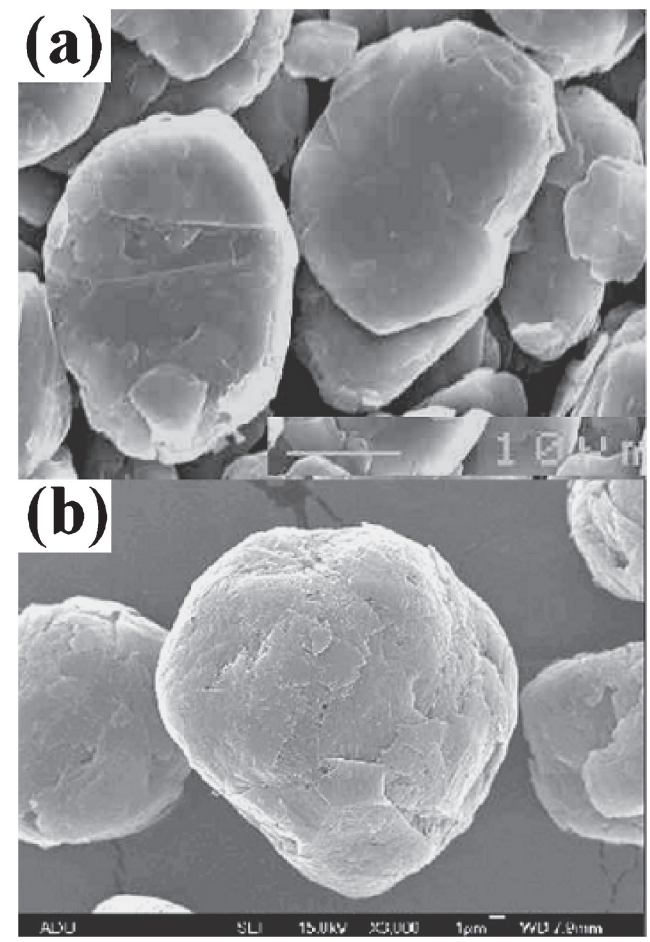

Figure 22. SEM images of rounded graphite used for the negative electrode active material of LIB. (a) Product in Korea, (b) Product in China.

spherically shaped graphite active materials (Fig. 22), whose outer surface is covered with graphene sheets through which passing of $\mathrm{Li}$ is believed to be impossible. While, these particles are conveniently used as the active material of the negative electrode.

An idea came up to mind of the author that the graphene sheets are not ideal but might have many holes as schematically shown in Fig. 23. We tried to find out the image of holes in the actual HTEM images in the published paper. Finally we could recognize the image of these holes as shown in the white squares in Fig. $24 .{ }^{28}$ Recently we could find the image of such hole on the graphene sheet imaged with ab initio calculation (Fig. 25). ${ }^{29}$

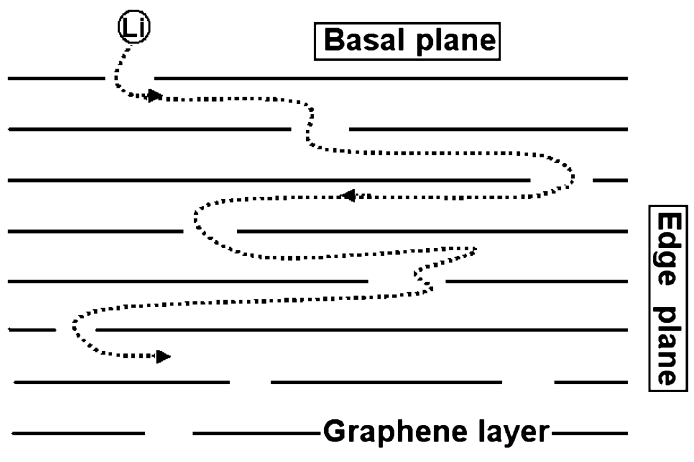

Figure 23. Schematic model of cross section of graphite having holes in the graphene planes.

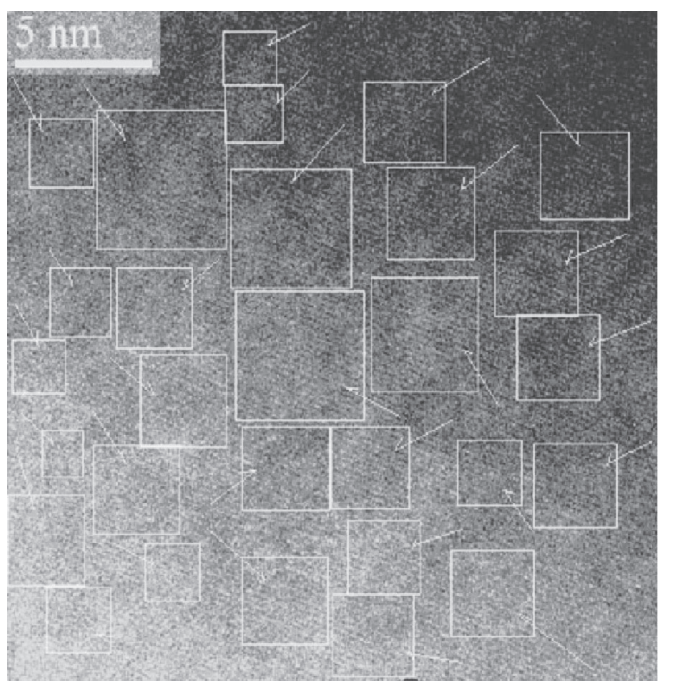

Figure 24. HRTEM image of graphite crystal wherein a number of holes are present, which is indicated with the aid of white square.

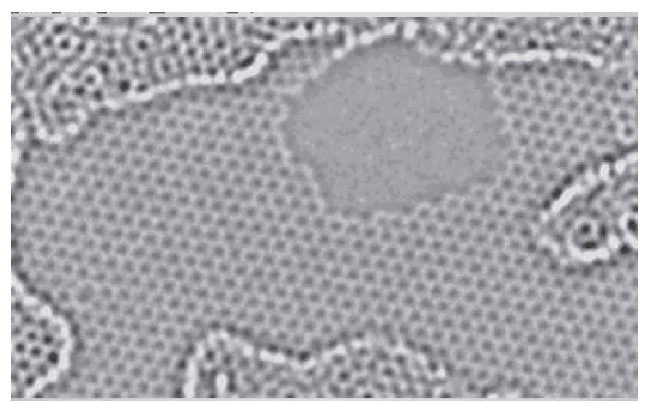

Figure 25. Top view of graphene layers having holes illustrated by ab initio computations. Courtesy Zettle Research Group. Laurence Berkeley National Laboratory and University of California at Berkeley. ${ }^{29}$

\section{Key Factor for the Improvement of Charge/Discharge Cycle Performance}

As a consultant the author was teaching the method of production on the rounded graphite in 2000 at Sodiff Advanced Material Co., Ltd. in Youngju, Korea. The formation of the rounded graphite particles was done by violent blowing the as obtained natural graphite particles into ultra high speed rotating drum, whereby each graphite particles undergo through high shearing stress to form 

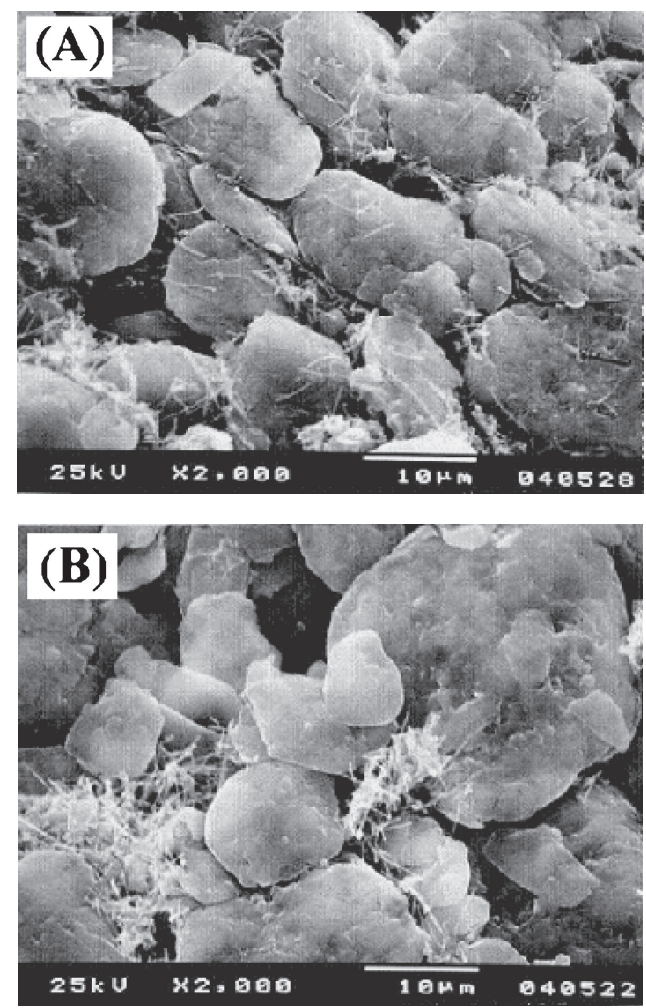

Figure 26. SEM images of the surface of negative electrode coated with rounded graphite and VGCF. (A) VGCF is dispersed homogeneously, (B) VGCF is agglomerated.

rounded shape. Petroleum pitch was applied as a binder during the rounding process, the author recommended to apply appropriate heat-treatment for obtaining mechanically stabilized material. Examples of the SEM images of the rounded graphite are shown in Fig. 22. The shape is convenient for fabricating coated electrode. In general graphite crystal is highly anisotropic and the electric conductivity along the c-axis direction (perpendicular to the basal plane) is very poor, which is inconvenient as the coated electrode. The rounded graphite, however, is isotropic macroscopically, and accordingly, the electric conductivity is high enough independent of the direction.

The anode sheet was fabricated by coating the prepared slurry comprised of the rounded graphite powders, binder, conductive additives, and solvent on a surface-treated $15 \mu \mathrm{m}$ thick copper foil. An example of the formulation of the slurry was: $94 \%$ graphite active material, $2 \%$ SBR binder with $2 \% \mathrm{CMC}$, and $2 \%$ conductive additive. Even though the rounded graphite is good electroconductor the microscopic topological conductivity of the coated electrode is very inhomogeneous since the mutual particle-toparticle contact among the active material particles is inhomogeneous. The anode performance of the coated electrode is highly dependent of the conductivity distribution throughout the electrode.

The conductive additive assists to fabricate a highly and homogeneously conductive electrode. Vapor grown carbon fiber (VGCF, Showa Denko made) was used as an excellent conductive additive in spite of its high price. The example of the SEM images of the coated electrode is shown in Fig. $26,{ }^{30,31}$ where we see the VGCF as a number of white thin needle-like lines on the rounded graphite particles. Figure 26(A) shows that the VGCF fibers are sticking tightly on the graphite particle surface and connecting each particle together just like electric cables, while Fig. 26(B) shows the VGCF to be agglomerated and not homogeneously distributed. Comparison of the results of cycle test obtained with the two samples will be shown. The charge/discharge cycle test was
Courtesy of Mr. Endo K former gradhate student of Rikkyo University. Depariment of Chemistry. Tokyo, Japan) (200d)

(A) Homogeneously coated; (B) Inhomogeneously coated. $\downarrow$ charge $\downarrow$ discharge
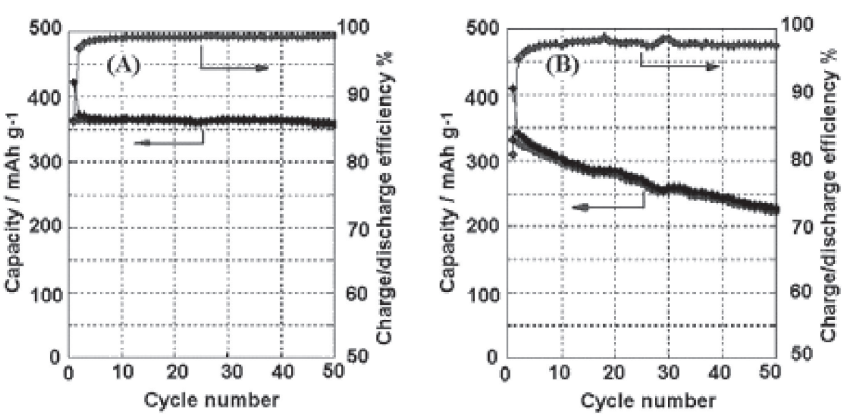

Figure 27. Constant current charge/discharge cycle performance under $1.5 \mathrm{C}$ rate of rounded graphite coated electrode in EC/DMC containing $1 \mathrm{M} \mathrm{LiClO}_{4}$. (A) Obtained with sample (A) in Fig. 26, (B) Obtained with sample (B) in Fig. 26. Courtesy of Mr. Koji. Endo, former graduate student of Rikkyo University.

performed under $1 \mathrm{C}$ rate for both charging and discharging at an ambient temperature with an electrolyte comprised of $1: 1(\mathrm{v} / \mathrm{v})$ mixture of ethylene carbonate and dimethyl carbonate containing $1 \mathrm{M}$ lithium perchlorate. The results are shown in Fig. 27, 30,31 where we see the performance of (A) is excellent, while that of (B) is poor, in spite of using the same amount of the same active material. The results show that not only the choice of materials but also the fabrication procedure plays an important role for realizing acceptable battery products.

\section{Application to HEV and Large-Size Appliances}

Nowadays HEVs (hybrid electric vehicles) are in the spotlight due to energy saving. LIB attracted attention as the power source for HEV. As the anode active material graphite is not recommended due to safety issues and lower power capability. In contrast, hard carbon having turbostratic arrays is suitable for this purpose since the rate of $\mathrm{Li}$ insertion/extraction is much higher than that of graphite, and in addition, the insertion potential is more anodic to ensure safety.

In case of HEV (hybrid electric vehicle) one has to bear in mind that the charging/discharging program and the loading current change very rapidly, Conventional LIB having graphite anode cannot follow the powering of such a rapid irregular changes. In contrast a carbonaceous material comprised of turbostratic structure array (TSA) has not only a wider spacing of graphene layers but also giving no stage structure during $\mathrm{Li}$ insertion. These properties realize very rapid reaction rate for $\mathrm{Li}$ insertion and extraction, which is favorable to the very high power capability. In addition this battery should be extremely robust and safe even during heavy working. TSA material is really the suitable material for this purpose even though the specific capacity is lower than that of graphite. The turbostratic carbons are prepared by heating mesophase carbon at $1500-2200^{\circ} \mathrm{C}$.

The CV curves obtained with the above prepared samples were evaluated and the peak current obtained at different potential scan rates were plotted against square root of the scan rate in Fig. 28, which shows straight lines whose slope is proportional to the diffusion rate in the carbon matrix. From this figure we see that the diffusion rate of $\mathrm{Li}$ in the matrices is the highest for the carbon fiber fired at the lowest temperature.

Dr. Kobayakwa of Kanagawa University was very kind to fabricate the glow discharge system for activation. The fired sample was activated further by exposing it in the glow discharge field. The glow discharge tube was constructed by sealing two disk electrodes, 


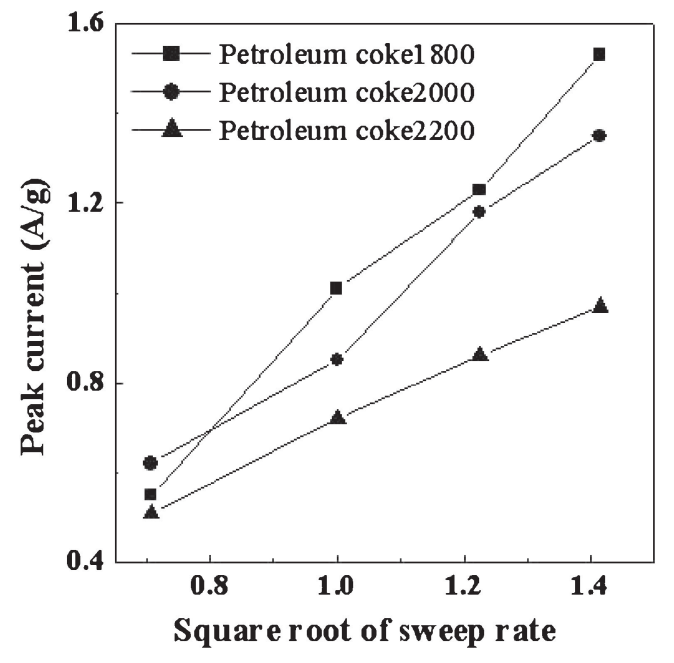

Figure 28. Plotting of peak height of CVs obtained with CFs fired at different temperatures against square root of the potential scan rate. Measured in EC/DMC containing $1 \mathrm{M} \mathrm{LiClO}_{4}$.

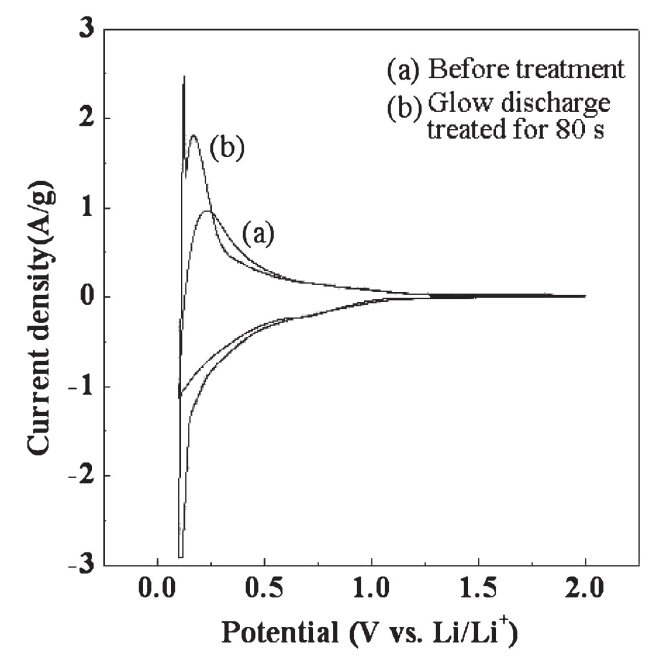

Figure 29. $\mathrm{CVs}$ obtained with $1800^{\circ} \mathrm{C}$ fired $\mathrm{CF}$ (Toho Tenax) in EC/DMC containing $1 \mathrm{M} \mathrm{LiClO}_{4}$. (a) Pristine, (b) Activation-treated with glow discharge.

and high tension $\mathrm{AC}$ voltage was applied to the electrodes from the AC source of Geisler tube. The CVs of $1800^{\circ} \mathrm{C}$ fired CF are shown in Fig. 29 for the sample before (a) and after (b) the activation treatment. As shown in the figure the CV peak on (b) was not only sharpened but also peak-enhanced remarkably. A sharp peak on (b) due to the Li UPD peak appeared to imply the removal of surface contamination. In conclusion, we successfully could provide a favorable active material for the anode of LIB suitable for the power source of HEV. ${ }^{32}$

The discharge curve of hard carbon is not flat but lowering at large discharging amount. Such a tendency is useful for detecting the state of charge. Mixing of turbostratic carbon with hard carbon may provide more convenient active material for vehicle or motor appliances.

\section{Characterization of Carbons for Capacitors}

\subsection{Introduction}

Electric and electronic circuits consist of power sources devices, semiconductor devices, resistors, capacitors, inductance devices, and lead wires. Therefore, capacitors are one of the most important passive devices in electric and electronic circuit. There are several different types of capacitors such as electrolytic capacitors, tantalum capacitors, metal film capacitors, ceramic capacitors, and electric double layer capacitors (EDLC). Among them carbon materials are essential materials.

The main functions of capacitors are: coupling and decoupling, buffering of current fluctuation, power smoothing, alternate current filtering, CR timer, memory back-up for PC and other electronic appliances.

\subsection{Electric double-layer capacitors (EDLC)}

In an attempt to enhance the capacitance of the super-capacitor we tried to apply a novel idea of nano-ionics concept. ${ }^{33}$ Maier and coworkers proposed a novel Li storage mechanism in the "nanoionics" system, where additional amount of $\mathrm{Li}$ can be stored in the SEI region of nano-size metal oxides. Oxide of $\mathrm{Ru}$ was the typical example. ${ }^{33}$ Application of this novel concept to modify the carbonaceous material having a large specific surface area is attractive. In this investigation we would like to show the capacitance enhancement phenomenon on a commercially available AC. For the performance evaluation experiment of such a new system, choice of fiber type AC is favorable since it enables us to use no binder and no conductive additive for the test electrode preparation, where we need not to worry about on the interfering influence of these materials.

The highlight of this experiment is the surface modification on the surface of an activated carbon fiber with oxides of such transition metals as $\mathrm{Pd}, \mathrm{Ag}, \mathrm{Cu}$, or $\mathrm{Sn}$, instead of $\mathrm{Ru} .{ }^{34}$

At first, the AC fiber felt was soaked in an aqueous concentrated solution of salt of the transition metal and the solution was boiled overnight, then the felt was taken off, the adhering solution being wiped off, followed by drying and heated at $400^{\circ} \mathrm{C}$ for 5 hours to form the oxide of the metal.

A slice of the fiber felt thus treated was sandwiched between a folded expanded metal, followed by spot-welding at several points of the peripheral of the sandwich and measuring the $\mathrm{CV}$ in an electrolyte of EC/DMC $(1: 1, \mathrm{v} / \mathrm{v})$ containing $1 \mathrm{M} \mathrm{LiClO}_{4}$.

The CVs of the surface treated AC fiber sample are shown in Fig. 30, where we see the charging/discharging current was enhanced up to 3-4 times as compared with those of untreated fiber. Especially, a strong peak due to Li deinsertion can be recognized at about 0.2 to $0.3 \mathrm{~V}$ vs. $\mathrm{Li} \mid \mathrm{Li}^{+}$, indicating high rate capability which is very favorable for HEV application.

\section{Conclusions}

The author has been engaged in the study of carbonaceous material since 1980 mainly on the application on the electrode system of batteries. Carbon is very interesting element since sometimes it is black colored electric conductive, but in sometimes it is the most brilliant jewel, diamond, which is hardest and a good thermally conductive but electrically insulating. Apart from diamond it appears to be inconspicuous like soot. The author is quite much interested in Carbon, which may be due to the experience of calligraphy. Wooden plate painted with soot paint characters serves us to keep archeological culture memory in our history. But anyhow, it is really inconspicuous, which has been overturned recently, i.e., initiated by Dr. Iijima on carbon nanotubes, ${ }^{35}$ followed by Novel Prize gettings on findings on fullerrene and on graphene.

Carbon is the source of life on the earth. There would be no more important element other than carbon. The field of the author's work on carbon may be less than nano-hole but the author had experienced profound depth. The author's desire is that the reader is stimulated to be interested in "carbon" for scientific curiosity. 

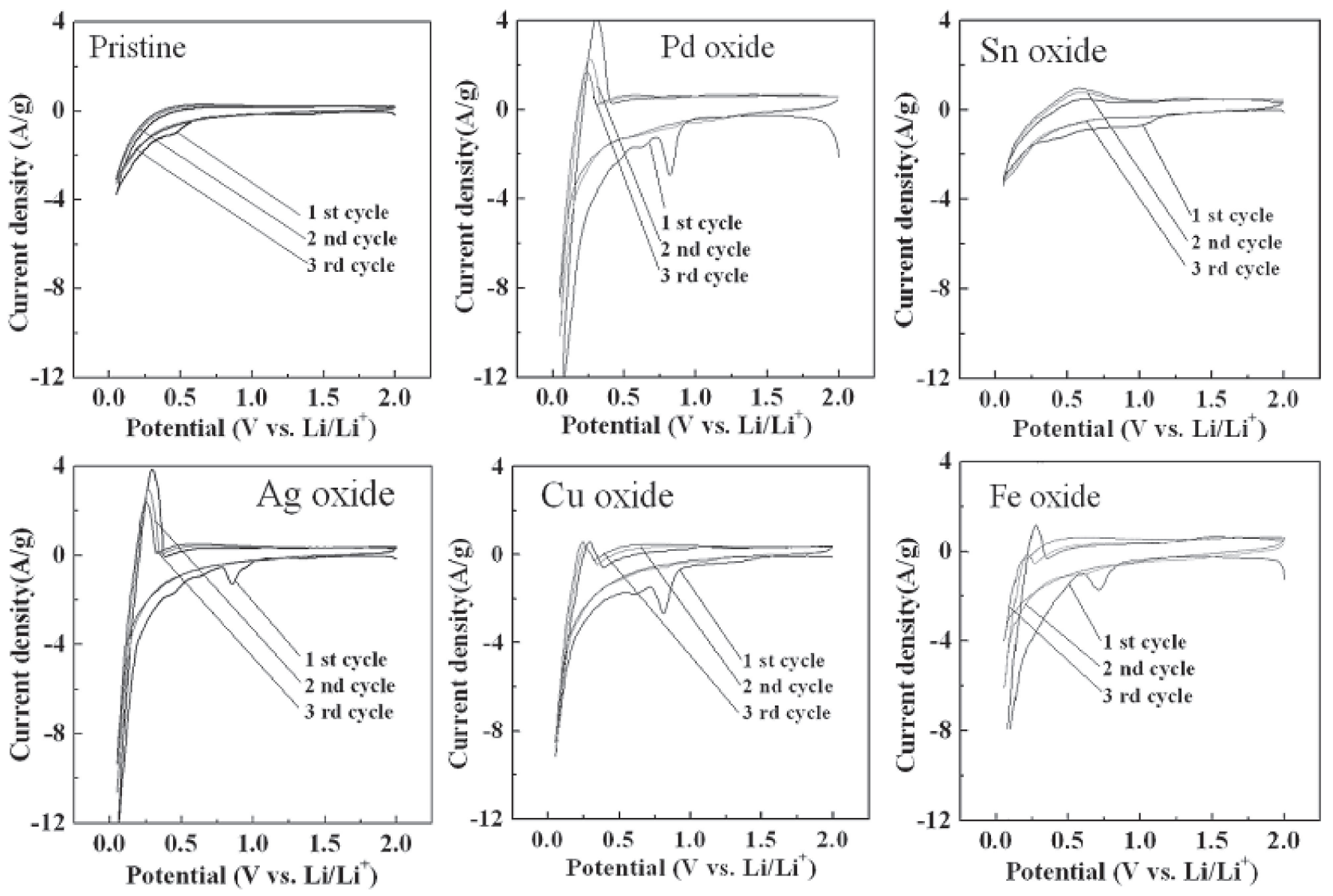

Figure 30. CVs obtained with activated CFs (Toho Tenax Co., Ltd.) whose surface was modified by coating with transition metal oxide films on the basis of Maier Effect. The CV scan was done in EC/DMC containing $1 \mathrm{M} \mathrm{LiClO}_{4}$ with a potential scan rate of $10 \mathrm{mV} \mathrm{s}^{-1}$.

\section{References}

1. T. Takamura, Encyclopedia of Electrochemical Power Sources (Editor-in-Chief: J. Garche), Elsevier Ltd., p. 709 (2009).

2. M. Nagashima, T. Mine, Y. Ikezawa, and T. Takamura, J. Power Sources, 43, 611 (1993).

3. M. Inagaki (Ed.), Carbon Family, Agune Shofu Sha Publishing Co., Tokyo, Japan, p. $80(2001)$.

4. J. Ebana, Y. Ikezawa, and T. Takamura, Denki Kagaku (Electrochemistry), 61, 727 (1993).

5. H. Ishikawa, J. Suzuki, K. Sekine, and T. Takamura, 71st Annual Meeting of the Electrochemical Society of Japan, Abstr., p.197 (2004).

6. M. Uratani, R. Takagi, K. Sumiya, K. Sekine, and T. Takamura, Denki Kagaku (Electrochemistry), 66, 1146 (1998).

7. S. Waki, K. Dokko, T. Matue, and I. Uchida, Denki Kagaku (Electrochemistry), 65, 954 (1997).

8. K. Yamaguchi, Thesis, Master's Degree, Department of Chemistry, School of Science, Rikkyo University, (2000).

9. O. Omae, J. Suzuki, T. Katusta, K. Yamaguchi, F. Kikuchi, K. Sekine, T. Kawamura, and T. Takamura, Solid State Ionics, 152-153, 105 (2002).

10. T. Takamura, M. Kikuchi, H. Awano, T. Ura, and Y. Ikezawa, Ed. D. H. Doughty, B. Vyas, T. Takamura, and J. R. Huff, Material Research Society Symposium Proceedings, 393, p. 345 (1995)

11. M. Kikuchi, Y. Ikezawa, and T. Takamura, J. Electroanal. Chem., 396, 451 (1995).

12. E. Peled, C. Menachem, D. Bar-Tow, and A. Melman, J. Electrochem. Soc., 143, L4 (1996).

13. T. Takamura, H. Awano, T. Ura, and Y. Ikezawa, Anal. Sci. Tech., 8, 583 (1995).

14. T. Takamura, H. Awano, T. Ura, and K. Sumiya, J. Power Sources, 68, 114 (1997).

15. R. Takagi, K. Okubo, K. Sekine, and T. Takamura, Denki Kagaku (Electrochemistry), 65, 333 (1997).

16. J. Suzuki, M. Yoshida, Y. Nishijima, K. Sekine, and T. Takamura, Electrochim. Acta, 47, 3881 (2002).

17. F. Kikuchi, S. Eguchi, J. Suzuki, K. Sekine, and T. Takamura, Electrochemistry, 71, $1117(2003)$
18. T. Takamura, K. Sumiya, J. Suzuki, C. Yamada, and K. Sekine, J Power Sources, 81, 368 (1999).

19. M. Saito, K. Yamaguchi, K. Sekine, and T. Takamura, J. Solid State Ionics, 135, 199 (2000).

20. T. Takamura, H. Awano, R. Takasu, K. Sumiya, and K. Sekine, J. Electroanal. Chem., 455, 223 (1998).

21. D. Aurbach, M. L. Daroux, P. Faguy, and E. Yeager, J. Electroanal. Chem., 297, 225 (1991).

22. K. Yamaguchi, J. Suzuki, M. Saito, K. Sekine, and T. Takamura, J. Power Sources, 97-98, 159 (2001).

23. K. Yamaguchi, Thesis, Master's Degree, Department of Chemistry, School of Science, Rikkyo University, (2000).

24. J. O. Besenhard (Ed.), Handbook of Battery Materials, Wiley-VCH, Mainheim, Germany, p. 396 (1999).

25. J. Suzuki, M. Yoshida, C. Nakahara, K. Sekine, M. Kikuchi, and T. Takamura, Electrochem. Solid-State Lett., 4, A1 (2001).

26. J. Suzuki, O. Omae, K. Sekine, and T. Takamura, Solid State Ionics, 152-153, 111 (2002).

27. T. Ohzuku, Y. Iwakoshi, and K. Sawai, J. Electrochem. Soc., 140, 2490 (1993).

28. T. Takamura, K. Endo, L. Fu, Y. P. Wu, K. J. Lee, and T. Matsumoto, Electrochim. Acta, 53, 1055 (2007).

29. C.. Ö. Girit, J. C. Meyer, R. Erni, M. D. Rossell, C. Kisielowski, L. Yang, C.-H. Park, M. F. Crommie, M. L. Cohen, S. G. Louie, and A. Zettl, Science, 323, 1705 (2009).

30. L. J. Fu, K. K. Endo, K. Sekine, T. Takamura, Y. P. Wu, and H. Q. Wu, J. Power Sources, 162, 663 (2006).

31. K. Endo, J. Suzuki, K. Sekine, and T. Takamura, Electrochemistry, 74, 374 (2006).

32. Yo. Sato, K. Nagayama, Yu. Sato, and T. Takamura, J. Power Sources, 189, 490 (2009).

33. P. Balaya, A. J. Bhattacharyya, J. Jamnik, Yu. F. Zhukovskii, E. A. Kotomin, and J. Maier, J. Power Sources, 159, 171 (2006)

34. Yo. Sato, Yu. Sato, and T. Takamura, the 50th Battery Symposium in Japan, Abstr, p. 277 (2010).

35. S. Iijima, Nature, 354, 56 (1991). 